unless by the use of anæsthetics. For eight months I treated her with the utmost persistence, using the best means at my command, including galvanism. Finally I advised the removal of the ovaries, and the patient gladly accepted my proposition, preferring death, even, to a life of pain and misery. A consultation was held with Drs. Kimball and Bass, who confirmed my opinion.

The operation was performed a little over two months ago, and thus far her suffering has been entirely relieved. The ovaries were non-adherent; not larger than normal, but were perfectly studded with small cysts, and contained about a tablespoonful of serum.

CASE X. This patient, forty-one years of age, mother of one child, - born sixteen years ago, had enjoyed good health up to within two years, since which time she bas had a history of menorrhagia ; in fact, she was unwell a larger part of the time, and had grown quite pale and weak, so that she was unable to work.

I first saw her in consultation with Dr. Carolin, and diagnosticated fibroma of the uterus and cystic tumor of the right ovary of the size of a large orange, but with a pedicle that would admit of its being easily pushed up under the ribs and down to Poupart's ligament. Operative interference was advised and accepted, it being my purpose to remove the cyst together with the left ovary. Making a small incision in the median line, the cyst was soon reached and removed; also a subperitoneal pedunculated fibroid, of the size of a goose-egg, from the posterior part of the uterus. 'This little growth had escaped observation, for it lay in a position that could not be reached, either externally or by rectal or vaginal touch.

The left ovary, which I was very anxious to remove, was so firmly held by the fibroid uterus against the bony pelvis that I could not extricate it without doing damage, and was obliged to leave it. The patient made a good recovery, and left the hospital in four weeks from the time of the operation.

\section{THE RESULTS OF THE USE OF ANTIPYRINE AT THE BOSTON CITY HOSPITAL. ${ }^{1}$}

BY GEORGE B. SHATTUCK, M.D., visiting PHYBICIAN.

IN October, 1883 , with my colleague, Dr. F. W. Draper, I reported to this Society the effects of kairine as an antipyretic in typhoid fever, as shown by cases in which it was exhibited at the Boston City Hospital. In commenting on these cases I remarked " that the behavior of kairine as shown by them leads one to believe that a better antipyretic is possible, and that such will probably be ultimately arrived at, it may be by further experiments in the same direction which led to this discovery." Shortly after this was written, Professor Knorr, of Erlangen, and one of his assistants, succeeded in obtaining an alkaloid, a derivative of quinoline, of remarkable antipyretic properties, to which the name of antipyrine was given. Filehne, who introduced kairine to the profession in Germany, and who was a laboratory assistant of Professor Fischer, its dis-

1 Read before the Clinical Section of the Suffolk District Medical Society, May 13, 1885. coverer, made the first clinical experiments with antipyrine. 'This derivative of quinoline takes the form of a white crystalline powder, with but little taste, extremely soluble in water, especially in warm water; also soluble in wine. It is generally well borne by the stomach, even in large doses, and may be agreeably administered in wine or aromatics.

Kairine has already passed out of favor and out of use, as there were good reasons why it should; but antipyrine has met with a much greater and more uniform success. The different reports concerning its mode of operation and effects agree in all essential particulars ; its antipyretic influence is fully as marked as that of kairine, whilst the administration is less frequent, and the fall in temperature is rarely accompanied by the chills and tendency to collapse, so often attendant upon the action of kairine. Its administration, even in full doses, is rarely attended by other inconveniences than profuse sweating and a slight vomiting without distress. Exceptional instances do occur in which the vomiting is prolonged and trying, and of course in such one loses more than one gains by giving the drug.

In a small proportion of the cases at the City Hospital here, and in a larger percentage of some of the German reports, the exhibition of antipyrine was followed by a somewhat variable eruption, which, however, commonly resembles that of measles - an eruption occasioning no inconvenience, and disappearing not infrequently during the continued use of the medicine.

Filehne's experience led him to recommend that antipyrine be given in three hourly doses of two grammes each; and it was in that way that it was at first generally given to get the full antipyretic effect. Latterly various doses have been tried. At the City Hospital we have given it according to Filehen's formula; we have also given only one full dose of two grammes, followed by two others of one gramme each, and we have tried single doses of one gramme. In some cases, after the effect of the three two-gramme doses had been attained, single repeated doses of five grains were given, with the aim of keeping down the temperature.

The charts which are shown, and which were prepared by the Senior Medical House-officer, Dr. W. L. Munro, show the results of these different methods. The charts are of patients in my own service and in those of other members of the staff. Most of the cases are of typhoid fever; but there is one of facial erysipelas, several of pneumonia, one of scarlet fever, one of sunstroke. In the last case two grammes were given subcutaneously at one time, and the patient made a rapid recovery, though brought to the hospital with a temperature of $107^{\circ}$.

Antipyrine was administered in several cases of intermittent, without interrupting the chills and without appreciable effect. This failure was anticipated from our previous experiences with kairine. A few instances are reported from Germany, in which the periodicity of the attacks was broken temporarily by large doses; but such instances are exceptional, and no antiperiodic action has been claimed or can be allowed. All these coal-tar derivatives resemble quinine in their antipyretic action, but differ from it in lacking the specific antiperiodic action upon malarial conditions. 


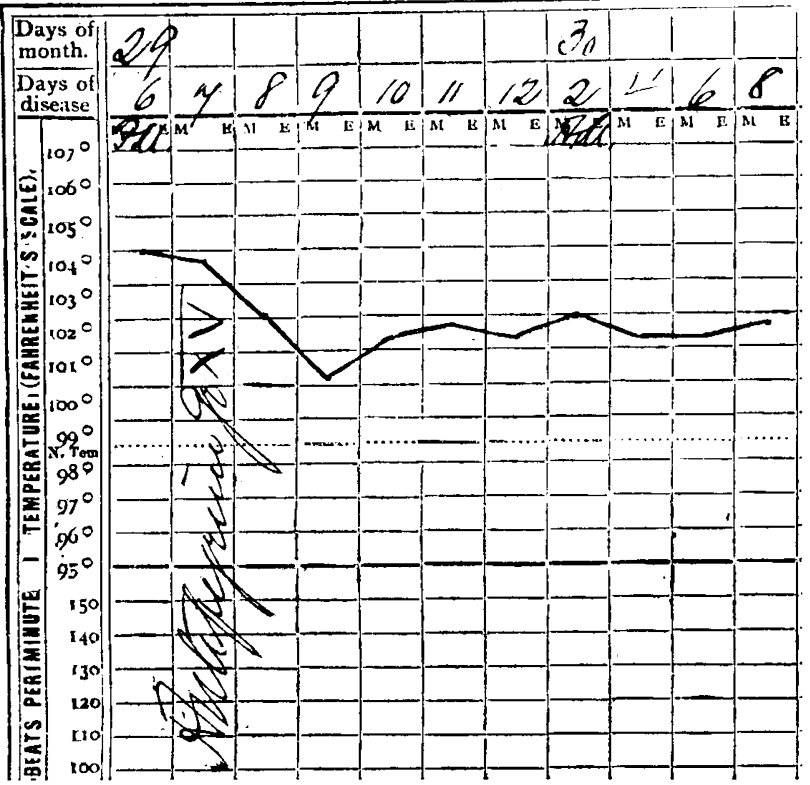

Female. Typhoid Fever. Days of Month. Hours of the Day.

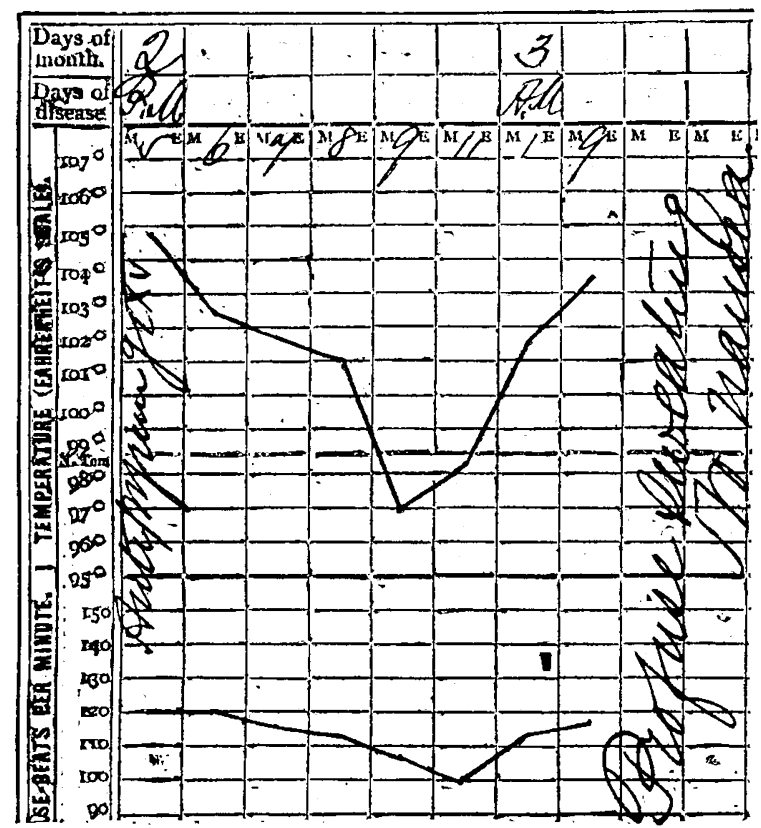

Female. Typhoid Fever. Days of Month. Hours of the Day.

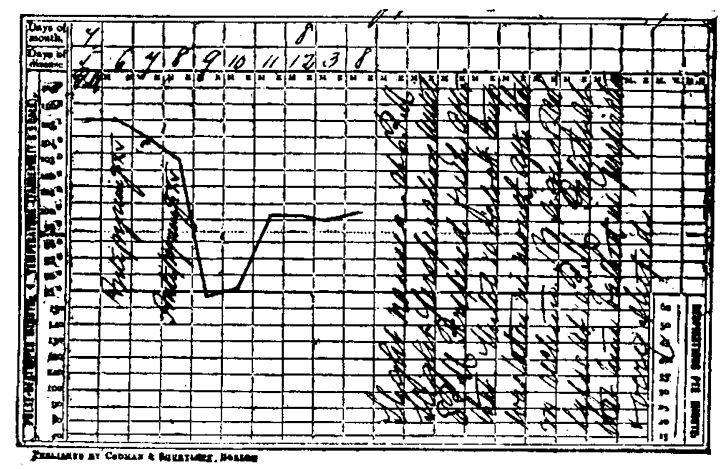

Female. Typhoid Fever. Days of Month. Hours of the Day.

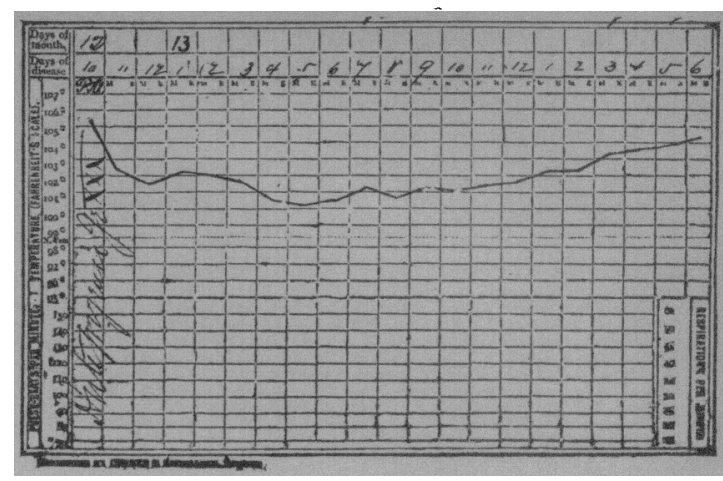

Female. Typhoid Fever. Days of Month. Hours of the Day.
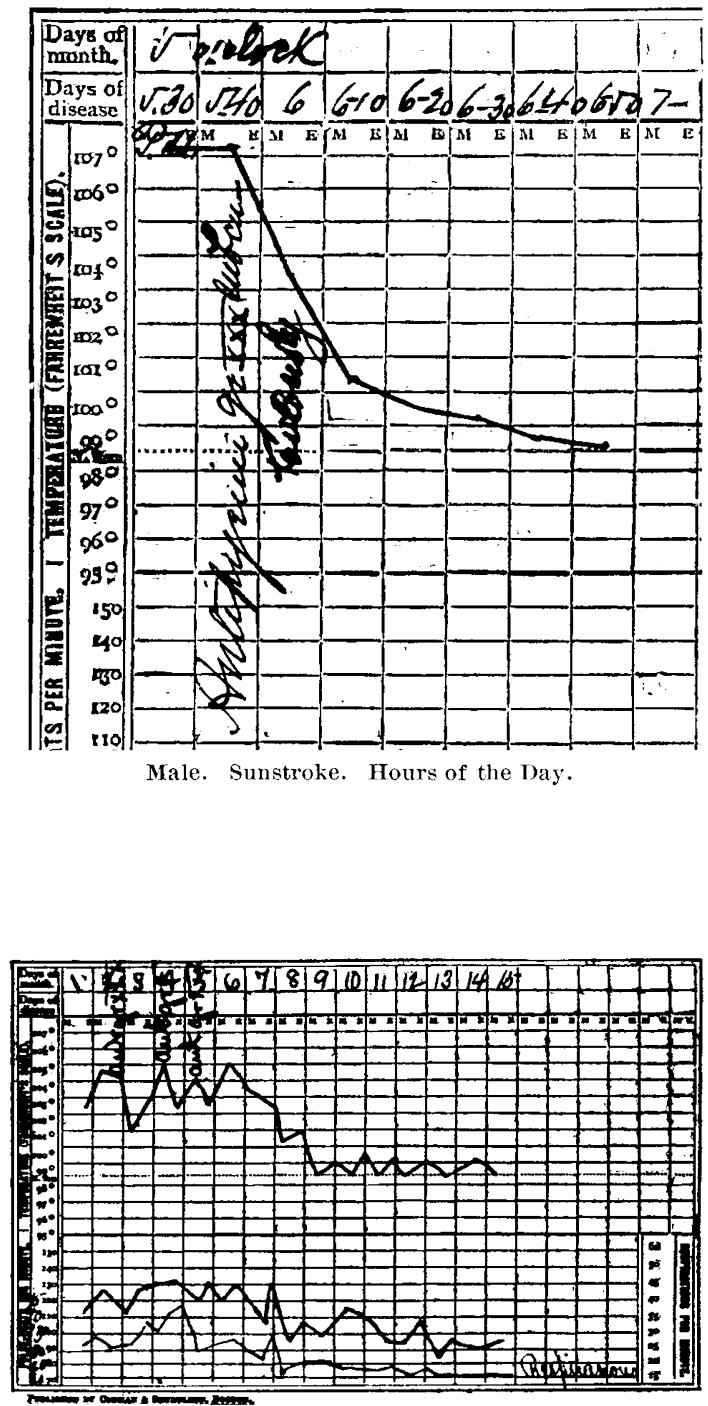

Female. Double Pneumonia. Three Thirty.grain Doses of Antipyrine on Three Successive Days. 
The fall in temperature ordinarily begins to declare itself in about an hour after giving antipyrine, reaching its maximum in from three to five hours after the full dose of six grammes, divided in the German fashion, continuing on an average about eight hours, though sometimes lasting twice as long. A fall of from three to five degrees $F$. is very easily secured. The change in the pulse is by no means always proportioned to that in the temperature. The urine is somewhat diminished, free from albumen, and but little altered in color - in the last respect offering a contrast to urine after kairine.

We have had no experience with antipyrine in children. Two ${ }^{2}$ of the German observers who used it largely in a children's clinic report that it is well borne by them, and suggest one decigramme for each year of age as a rule for the dose to be given.

Antipyrine has been in use at the Boston City Hospital since last June (1884), and was first suggested to me by Dr. F. H. Williams, who procured a small quantity and sent it to the hospital. An editorial notice of the drug will be found in the Boston Medical and Surgical .Journal of August 14, 1884. For some months the supply was limited and had to be husbanded; at present it is in better supply, at $\$ 1.25$ the ounce, and may be had of Jutz \& Movius, wholesale dealers, 37 Pearl Street, who import 200 ounces a week into New York to supply the country. 'The discoverer, I regret to say, put a patent upon the article, a proceeding which, however plentifully it may be prepared, will always be reflected in the price.

As a general result of our experience at the City Hospital, where further trials are still being made, I am able to endorse antipyrine as: (a) An efficient and reasonably safe antipyretic, withont antiperiodic qualities.

(b) Whose exhibition in proper doses is, as a rule, unattended by serious discomforts or drawbacks.

(c) By reducing a high temperature it frequently substitutes calm for excitement and sleep for restlessness.

(d) Otherwise it does not usually modify the course of disease, and certainly not of typhoid fever.

(e) The quality of the sample used must be carefully watched in these synthetical compounds. A poor article will produce vomiting, chills, and collapse, when a good one will not; or, on the other hand, may be inefficient when the pure drug would have proved effective.

Antipyrine may be employed in a variety of febrile conditions, though its desirability in phthisis is questioned; but typhoid fever is the disease in which it is likely to be most largely and frequently used. When used in typhoid it should be distinctly without expectation of modifying the course of the disease. To emphasize our own experience on this point I may quote that of Alexander, ${ }^{3}$ who reports a severe relapse in typhoid after the administration of fifty-four grammes of antipyrine in divided doses throughout the first attack; and of Dr. William $\mathbf{H}$. Draper, in whose service at the New York Hospital, ${ }^{4}$ of five patients dying from typhoid fever, one took ten grammes in ten doses during five days; a second

2 Pensoldt and Sartorius, Berlin. Klin. Woch., July 28, 1881.

Fortschritte dor Medicin, vol. i1. p. 678, 188 . twenty-seven grammes in seven doses during six days; a third thirty-four grammes in twenty-one doses during eight days; a fourth forty-eight grammes in ten doses during seven days; a fifth three hundred and twenty-one grammes in sixty-five doses during thirty days.

It is extremely probable that we have only just begun to make the acquaintance of these synthetical laboratory compounds, and that, as kairine was a prelude to antipyrine, so the latter will be followed by something even better.

Thallin 5 is another quinoline product with which clinical tests have lately been made in Germany. Its antipyretic action is more like that of kairine than of antipyrine. The fall in temperature begins generally in from two to three hours after administration, and is usually accompanied by sweating. The rise is rarely postponed more than four or five hours, and often less, in which case it is apt to be attended by a chill. Neither vomiting, cyanosis, nor collapse have been remarked. The fall and rise of temperature are, however, less gradual than with antipyrine. 'The dose is from a quarter to three quarters of a gramme.

The laborer is undoubtedly worthy of his hire, and mnch special chemical knowledge and laboratory work is required for the evolution of these compounds; but one regrets that they should be covered by patents. This is not in accordance with a true scientific or professional spirit, or with what the past has led us to expect from Germany, and it is to be hoped in the future, if her physiological chemists furnish the profession with new means for alleviating human suffering, it will be, as in the past, without commercial restrictions.

\section{Wogipital Oractice and Elimiral Metemoranda.}

\section{FLUID EXTRACT OF MANACA IN RHEU- MATISM.}

REPORT OF CASES TREATED AT THE BOSTON DISPENSARY BERVICE OF DR. G. M. GARLAND.

The following cases of rheumatism were treated with the fluid extract of manaca in the men's room of the Boston Dispensary during the winter of 1883 . The extract employed was furnished gratuitously by Parke, Davis, and Company, with the request that its merits might be tested :-

CASE I. R. J. C., twenty-eight years of age, muscular rheumatism, acute attack. The left arm was much swollen from the wrist to the elbow, was tender, painful, and helpless. Patient also complained of his leg. Temperature $98.2^{\circ} \mathrm{F}$. Ordered salicylate of soda.

Nov. 7th. No better. Stop salicylate of soda. Take fluid extract of manaca - fifteen drops every three hours.

Nov. 9th. Reports that leg is less lame, but arm is bad as ever. Increased the manaca to thirty drops four times daily.

Nov. 14th. Swelling of arm is nearly gone. Ankle is better, but patient still walks lame. Patient says he took salicylate of soda for one week

' V. Jacksch, Wiener Med. Wochschr., No. 48, 1884. 